\title{
Object-oriented Classification Technique for Extracting Abandoned Farmlands by Using Remote Sensing Images
}

\author{
Shixin Wang ${ }^{1}$, Wenjun $\mathrm{Li}^{2}$, Yi Zhou ${ }^{3}$, Futao Wang ${ }^{4}$, Qilong $\mathrm{Xu}^{5}$
}

\begin{abstract}
The abandonment phenomenon has become one of the most serious problems in China in the last 20 years. Preventing the farmland from abandonment is an urgent issue for authority. Thus, abandoned farmland monitoring is very important. The conventional field investigation approach of abandonment status cannot meet the demand of large area because of the lack of efficiency and timeliness. Remote sensing technology has applied in terms of investigation and assessment of arable land abandonment. Visual interpretation can extract abandoned farmlands accurately, but this method is inefficiency. Image classification is a method of automatic recognition by machine, but the commonly used pixel-based classification has poor result and low accuracy in extraction of abandoned farmlands. Object-oriented classification technique can provide efficiency and accuracy. In this work, SPOT-5 image was used for surveying and extracting the abandoned farmland. This paper introduces the theory, process and result of object-oriented classification for abstracting abandoned farmland on the basic of remote sensing, and compares the result with pixel-based classification's result.
\end{abstract}

\footnotetext{
${ }^{1}$ Shixin Wang

Institute of Remote Sensing and Digital Earth, Chinese Academy of Sciences, Beijing 100101, PR. China

${ }^{2}$ Wenjun Li $(\square)$

Institute of Remote Sensing and Digital Earth, Chinese Academy of Sciences, Beijing 100101, PR. China

University of Chinese Academy of Sciences, Beijing 100049, PR. China e-mail: jasper_lwj@163.com

${ }^{3}$ Yi Zhou

Institute of Remote Sensing and Digital Earth, Chinese Academy of Sciences, Beijing 100101, PR. China

${ }^{4}$ Futao Wang

Institute of Remote Sensing and Digital Earth, Chinese Academy of Sciences, Beijing 100101, PR. China

${ }^{5}$ Qilong Xu

China Centre for Resources Satellite Data and Applications, Beijing 100094, PR. China
} 
Keywords: abandoned farmland · remote sensing · object-oriented classification

\section{Introduction}

Abandoned farmland is a farmland that cannot be cultivated for some reason, therefore doesn't create economic value for years. Due to urbanization, desertification and the changing policies, the increase of agricultural land abandonment has become one of the main changes in land use in China over the recent years. In China, the abandonment phenomenon has existed since 1980s. It reduces grain outputs, and becomes more and more serious after 1990s [1]. A further increase of land abandonment is expected in the near future. It has become one of the most serious problems in the last 20 years. Abandoned farmlands make the land in a vicious circle. Abandoned farmlands can cause all sorts of consequences, such as soil erosion, landscape pattern change, biological process and characteristics change and agricultural production conditions deteriorated.On the one hand, lands are explored to increase food production; on the other hand, these explored lands are abandoned for various reasons. If the authorities want to bring more lands under cultivation, they must consider how to deter farmland being abandoned at first. It's an urgent issue. In addition, abandoned farmland monitoring can provide scientific evidence for food security, land use planning and economic development of China.

The researches about agricultural land abandonment were mainly concentrated on description of different types of abandoned phenomenon and analysis of the reasons. On the basis of field investigation, Chinese scholars' researches focused on the regional abandoned lands. The conventional investigation approach of abandonment status is field survey (simple or complete). However, field survey cannot meet the demand of large area because of the lack of efficiency and timeliness. Remote sensing technology has worked successfully in land utilization, land cover types and agricultural production assessment, but was seldom applied in extraction of arable land abandonment. NDVI time-series features was used for abstracting abandoned farmlands [2]. The MODIS NDVI data have high temporal resolution but low spatial resolution $(250 \mathrm{~m})$. As a result, if the area of the abandoned farmland is small, its features of NDVI time-series may be confused by other land covers.

The development of object-oriented classification methods suitable for medium to high resolution satellite imagery provides a valid alternative to 'traditional' pixel-based methods [3]. This paper compares the results of object-oriented classification to supervised pixel-based classification for abstracting abandoned farmland on the basic of SPOT-5 image. The object-oriented approach involved the segmentation of image data into objects. Objects were assigned class rules using spectral signatures, shape, texture and spatial locations. The supervised pixelbased classification involved the selection of training areas and a classification us- 
ing some algorithms [4]. Accuracy assessments of all classifications were undertaken.

\section{Data Acquisition}

SPOT-5 is the fifth satellite of the SPOT remote sensing satellite family. It is designed to ensure continuity of data acquisition and space image services. It carries two identical cameras named HRG (High Resolution Geometry) providing a $2.5 \mathrm{~m}$ and a $5 \mathrm{~m}$ resolution in a panchromatic mode and a $10 \mathrm{~m}$ resolution in a multispectral mode, keeping a $60 \mathrm{~km}$ ground field. The multispectral image consisted of four spectral bands (B1 to B4). Bands B1 (green: 0.50-0.59 $\mu \mathrm{m}$ ), B2 (red: 0.61$0.68 \mu \mathrm{m}$ ) and B3 (near infrared: $0.78-0.89 \mu \mathrm{m}$ ) had an initial resolution of $10 \mathrm{~m}$; band B4 (mid-infrared, 1.58-1.75 $\mu \mathrm{m}$ ) had a resolution of $20 \mathrm{~m}$ and was resampled at $10 \mathrm{~m}$. High-resolution panchromatic and multi-spectral SPOT-5 images $(2.5 \mathrm{~m}$ and $10 \mathrm{~m}$ ) taken on 8th November 2010 were used in this work.

\section{Study Area}

The study area is part of Pingqiao District of Xinyang City in Henan Province. The area is close to the Huaihe River. The region lies on the important geographic dividing line of the typical subtropical zone and the warm temperate zone of China, with sufficient heat condition, abundant precipitation and adequate light. Rice and wheat are massively produced in this region. Fig. 1 shows the image of the study area.
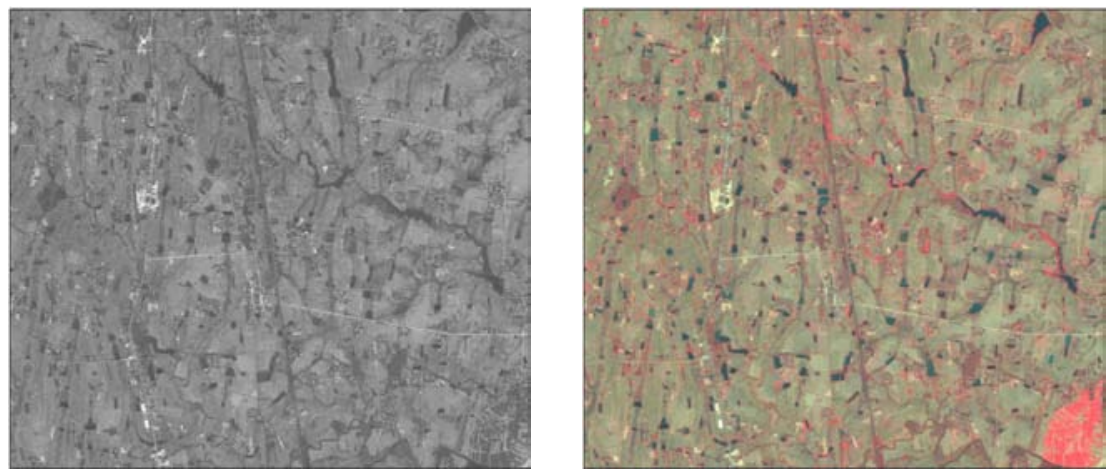

Fig. 1 SPOT-5 high-resolution panchromatic and multi-spectral images of the study area 


\section{Pixel-based Supervised Classification}

\subsection{Methodology}

The pixel-based classification was undertaken using ENVI v5.0 image processing software. This involved the selection of training areas representative of the eight land cover classes (buildings, water, wheat, rice, vegetable field, woodland, naked soil and abandoned farmland). A number of training areas were selected to represent each class. The spectral mean of the training area was then used to determine to which class the pixels were assigned. Six different supervised classification algorithms were used to classify different types of land cover by SPOT-5 image, and then abstracted abandoned farmlands.

\subsection{Results}

Accuracy assessments were undertaken using confusion matrices and Kappa statistics. The accuracy of the classified image was the assessed using field data collected in the study area and visual interpretation of the area. It can be seen from Table 1 that the accuracy of maximum likelihood classification was higher than others. Nonetheless, pixel-based supervised classification had low accuracy for abandoned farmland extraction.

Table 1 Accuracy of pixel-based supervised classification results

\begin{tabular}{cccc}
\hline $\begin{array}{c}\text { Supervised Classification } \\
\text { Method }\end{array}$ & $\begin{array}{c}\text { Overall Accura- } \\
\text { cy (\%) }\end{array}$ & $\begin{array}{c}\text { Overall Kappa } \\
\text { Coefficient }\end{array}$ & $\begin{array}{c}\text { Abandoned Farm- } \\
\text { land Classification } \\
\text { Accuracy (\%) }\end{array}$ \\
\hline Maximum Likelihood & 82.3447 & 0.7942 & 59.00 \\
Parallelepiped & 35.7096 & 0.2620 & 18.41 \\
Minimum Distance & 58.3755 & 0.5208 & 57.43 \\
Mahalanobis Distance & 72.6055 & 0.6827 & 62.02 \\
Spectral Angle Mapper & 58.7013 & 0.5210 & 59.72 \\
Spectral Information Di- & 27.6683 & 0.1676 & 44.02 \\
vergence & & & \\
\hline
\end{tabular}

Fig 2 is a visual comparison of the resultant abandoned farmland extraction images shows the differences between the classifications. Pixel-based supervised classification distinguishes the objects which have different spectral characteristics. Due to the abandoned farmland is mixed by weeds, soil and water; the spectral characteristics of it are very complex. Because of this, classification created 
poor results, and pixel-based supervised classification is infeasible for abandoned farmland extracting.

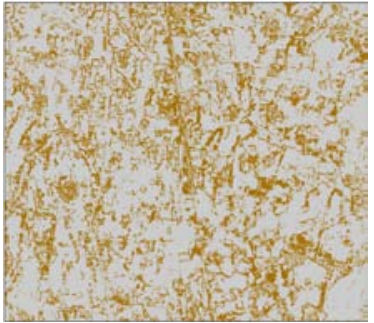

(a)

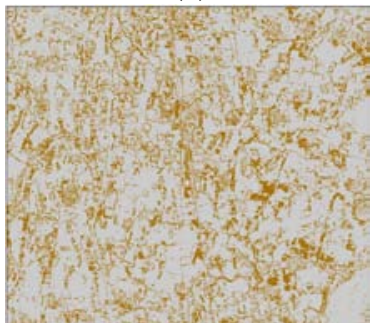

(d)

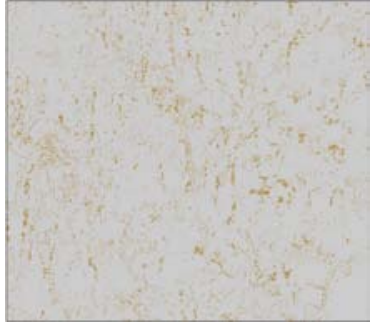

(b)

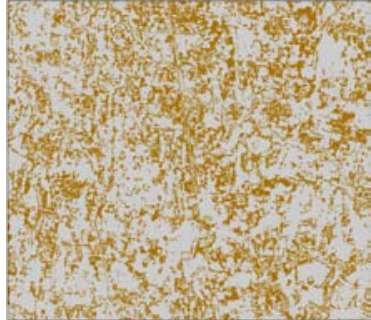

(e)

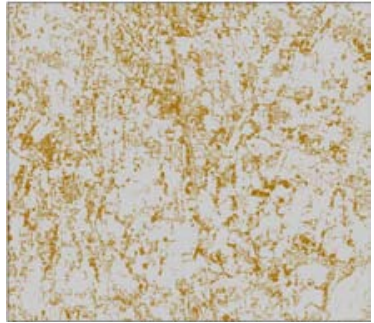

(c)

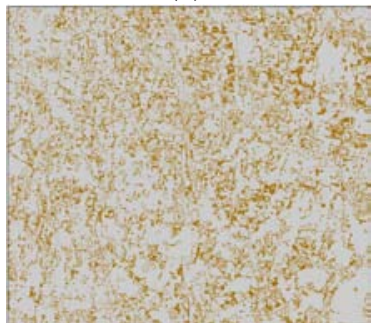

(f)

Fig. 2 Abandoned farmland extraction results by pixel-based classifications: (a) maximum likelihood; (b) parallelepiped; (c) minimum distance; (d) mahalanobis distance; (e) spectral angle mapper; (f) spectral information divergence.

\section{Object-oriented Classification}

\subsection{Methodology}

The object-oriented classification conducted using feature extraction tool in ENVI v5.0 image processing software. This method is based on the integrated use of high-resolution panchromatic and multi-spectral images for object-oriented land cover classification. Object-oriented classifications require identifying meaningful objects over the image and labeling them with class attributes. Object identification is performed by image segmentation techniques and object labeling by applying classification techniques. Therefore, the overall procedure consists of a sequential application of segmentation and classification [5]. 


\subsubsection{Segmentation}

Segmentation principally means the grouping of picture elements by certain criteria of homogeneity [6]. An object is any real entity the user intends to classify. Image segmentation techniques make use of both spectral information (feature vector of the pixels) and spatial information (size, shape and adjacency to other pixels) to identify and delineate suitable segments within an image. In this work, edge-based segmentation algorithm was selected which is provided by ENVI.

Edge-based segmentations attempt to find segment boundaries by detecting edges between image areas with different characteristics. Subsequently, image regions that are completely surrounded by edge pixels become segments. As a result, the image pixels can either belong to a segment or form a boundary. Fig 3 shows the object-oriented approach involved the segmentation of the SPOT-5 image data into objects.

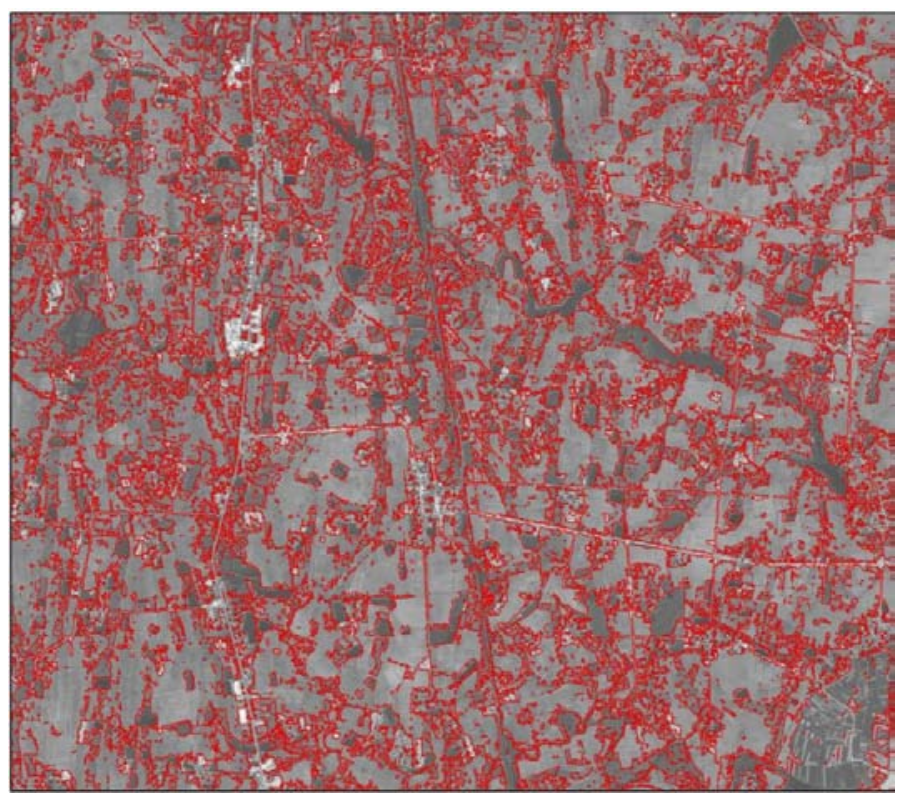

Fig. 3 Segmentation of the study area

\subsubsection{Classification}

Sample objects were selected as representative of land cover classes. A total of eight land cover classes for the study area were identified based on visual interpretation. Class rules for the objects were then developed using spectral signatures, shape, texture, spatial location and the contextual relationships of the objects. 
These rules were then used as a basis for classification of the image. Samples for each class were selected from the image objects to act as training areas for the classification.

\subsection{Results}

The method of accuracy assessment has previously been described. Fig 4 is the resultant abandoned farmland extraction image by using object-oriented classification. Visually, the extraction result significantly outperformed the result of pixelbased supervised classification. The shape and distribution of abandoned farmlands are more closed to reality. From the results of the confusion matrices, the overall accuracy and overall Kappa of the object-oriented classification were $91.4308 \%$ and 0.8721 , while the abandoned farmland classification accuracy was $78.94 \%$. It is observed that object-oriented classification appears to be able to extract more accurately abandoned farmlands.

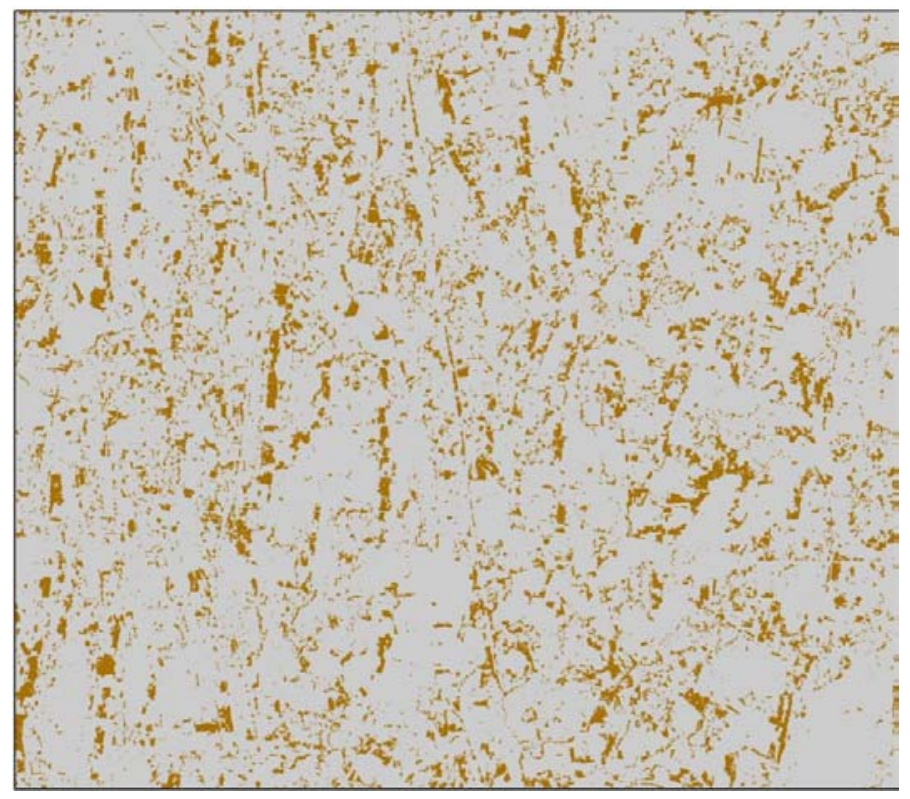

Fig. 4 Abandoned farmland extraction result by object-oriented classification 


\section{Discussions and Conclusions}

This paper proposed a method for object-oriented classification based on the highresolution panchromatic and multi-spectral images to extract abandoned farmlands of a study area in Xingyang City. Due to the abandoned farmland is mixed by weeds, soil and water; the spectral characteristics of it are very complex. Therefore, commonly used pixel-based supervised classification created poor results, and it is infeasible for abandoned farmland extracting. The object-oriented method use in this paper provided result with an acceptable accuracy much better than the pixel-based classification.

This suggests that object-oriented classification has great potential for extracting abandoned farmlands from satellite imagery. To improve the accuracy of the object-oriented classification, further work refining the process is continuing. The use of multi-sensor data and ancillary data, such as DEM data sets and GIS layers, is being investigated.

\section{Acknowledgments}

This work was supported by the Agriculture Science Technology Achievement Transformation Fund (No. SQ2011EC4910019) and the National Science and Technology Supporting Projects of China (No. 2011BAH23B03).

\section{References}

1. C. W. Liu, X. B. Li (2006) "Regional Differences in the Changes of the Agricultural Land Use in China during 1980- 2002”. Acta Geographica Sinica, 61, 139-145.

2. W. F. Cheng, Y. Zhou, S. X. Wang, Y. Han, F. T. Wang, et al. (2011) "Study on the Method of Recognizing Abandoned Farmlands Based on Multispectral Remote Sensing," Spectroscopy and Spectral Analysis, 31, 1616-1620.

3. Benz, U., Hofmann, P., Willhauck, G., Lingenfelder, I., \& Heynen, M. (2004), "Multiresolution, object-oriented fuzzy analysis of remote sensing data for GIS-ready information". ISPRS Journal of Photogrammetry and Remote Sensing, 58, 239-258.

4. T. Whiteside, Ahmad, W (2005) A comparison of object-oriented and pixel-based classification methods for mapping land cover in northern Australia. Melbourne: Spatial Sciences Institute.

5. D. Geneletti \& B. G. H. Gorte (2003) A method for object-oriented land cover classification combining Landsat TM data and aerial photographs, International Journal of Remote Sensing, 24:6, 1273-1286, DOI: 10.1080/01431160210144499

6. G. Willhauck (2000) Comparison of object oriented classification techniques and standardimage analysis for the use of change detection between SPOT multispectral satellite images and aerial photos. ISPRS, XXXIII. 